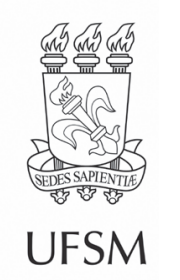

\title{
Artigos
}

\section{Efeito de retardantes de fogo sobre a germinação de espécies florestais tropicais}

\author{
Effect of fire retardants on the germination of tropical forest species
}

\author{
Josiane Fernandes Keffer ${ }^{\oplus}$, Adilson Pacheco de Souza ${ }^{\oplus}$, \\ Rogério Antonio dos Santos ${ }^{\oplus}{ }^{\text {, Daiane Cristina de Lima }}{ }^{\oplus}$, \\ Mariana Pizzatto ${ }^{\oplus}$, Andréa Carvalho da Silva ${ }^{\oplus}$ \\ 'Universidade Federal de Mato Grosso, Sinop, MT, Brasil
}

\section{RESUMO}

Objetivou-se avaliar o efeito de diferentes concentrações de retardantes de fogo e de um polímero hidrorretentor sobre a germinação de sementes das espécies florestais tropicais Handroanthus impetiginosus (ipê-rosa), Tabebuia roseoalba (ipê-branco), Enterolobium schomburgkii (faveira) e Schizolobium parahyba var. amazonicum (paricá). Destaca-se que não foram realizadas comparações entre os produtos, pois estes apresentam diferentes recomendações comerciais e composições químicas. As sementes foram submetidas a soluções de três retardantes de fogo nas seguintes concentrações: i) Phos-Chek WD881 $®$ a 0,0; 0,1; 0,3; 0,6; 0,8 e 1,0 mL L-1; ii) Hold Fire ${ }^{\circledR}$ a 0,0; 0,7; 0,9; 1,$1 ; 1,3$ e $1,5 \mathrm{~mL} \mathrm{~L}^{-1}$; e iii) polímero hidrorretentor Nutrigel $\circledast$ a 0,$00 ; 0,10 ; 0,25 ; 0,50 ; 0,75$ e $1,0 \mathrm{~g} \mathrm{~L}^{-1}$. Foram avaliadas quatro repetições de 100, 100, 30 e 25 sementes para as espécies supracitadas, em delineamento inteiramente casualizado. Os testes de germinação foram conduzidos em câmaras de germinação a $30^{\circ} \mathrm{C}$ e fotoperíodo de $12 \mathrm{~h}$, por 14 dias. Avaliaram-se: porcentagem de germinação, primeira contagem de germinação, índice de velocidade de germinação, tempo médio de germinação e vigor de plântulas. O Phos-Chek WD881 reduziu a velocidade de germinação dos ipês e a primeira contagem de germinação e quantidade de plântulas normais dessas espécies e do paricá. O Hold Fire influenciou na porcentagem de germinação do ipê-rosa (máximo de 97,0\% em 1,1 mL L-1) e na velocidade de germinação do ipê-branco, mas não causou variações no vigor das plântulas. O polímero hidrorretentor não influenciou na germinação, mas causou redução de 14,3\% de plântulas normais para o paricá. Em geral, Phos-Chek WD881 pode ser fitotóxico para o ipê-branco, ipê-rosa e paricá, quando aplicado em concentrações $\geq 0,6 \mathrm{~mL} \mathrm{~L}^{-1}$; Hold Fire pode promover a germinação do ipê-branco e do ipê-rosa, sem efeitos para as demais espécies; e o polímero hidrorretentor não exerceu nenhum efeito sobre a germinação de sementes das espécies florestais avaliadas.

Palavras-chave: Sementes florestais; Processo germinativo; Fitotoxidade; Retardantes de fogo 


\begin{abstract}
The objective of this study was to evaluate the effect of different concentrations of fire retardants and water-retaining polymer on seed germination of tropical forest species Handroanthus impetiginosus (ipêrosa), Tabebuia roseoalba (ipê-branco), Enterolobium schomburgkii (faveira) and Schizolobium parahyba var. amazonicum (paricá). It is noteworthy that no comparisons were made between the products, as they have different commercial recommendations and chemical compositions. The seeds were submitted to solutions of three fire retardants in the following concentrations: i) Phos-Chek WD881 ${ }^{\circledR}$ at $0.0 ; 0.1$; $0.3 ; 0.6 ; 0.8$ and $1.0 \mathrm{~mL} \mathrm{~L}^{-1} ;$ ii) Hold Fire ${ }^{\circledR}$ at $0.0 ; 0.7 ; 0.9 ; 1.1 ; 1.3$ and $1.5 \mathrm{~mL} \mathrm{~L}^{-1}$; and iii) water-retaining polymer Nutrigel $\circledast$ at $0.0 ; 0.10 ; 0.25 ; 0.50 ; 0.75$ and $1.0 \mathrm{~g} \mathrm{~L}^{-1}$. Four replicates of 100, 100, 30 and 25 seeds were evaluated for the aforementioned species, in a completely randomized design. The germination tests were conducted in germination chambers at $30^{\circ} \mathrm{C}$ and 12 hours of photoperiod for 14 days. It was evaluated: germination percentage, first germination count, germination speed index, average germination time and seedling vigor were evaluated. Phos-Chek WD881 reduced the germination speed of the ipês and the first germination count and number of normal seedlings of these species and paricá. Hold Fire influenced the germination percentage of ipê-rosa (maximum $97.0 \%$ in $1.1 \mathrm{~mL} \mathrm{~L}^{-1}$ ) and the germination speed of ipê-branco, but did not cause variations in seedlings vigor. The water-retaining polymer did not influence germination, but caused a $14.3 \%$ reduction of normal seedlings to paricá. In general, Phos-Chek WD881 can be phytotoxic to ipê-branco, ipê-rosa and paricá, when applied in concentrations $\geq 0.6 \mathrm{~mL} \mathrm{~L}^{-1}$; Hold Fire can promote the germination of ipê-branco and ipê-rosa, without effects for the other species; and the water-retainng polymer had no effect on the seed germination of the evaluated forest species.
\end{abstract}

Keywords: Forest seeds; Germination process; Phytotoxicity; Fire retardants

\title{
1 INTRODUÇÃO
}

Os incêndios florestais estão entre os fatores responsáveis por inúmeros impactos econômicos, sociais e ambientais em diferentes regiões (LATHA; KUMAR, 2016; SOARES; BATISTA; TETTO, 2017) e têm causado preocupações em função das perdas da biodiversidade, alterações no balanço de carbono de áreas florestadas, incremento de aerossóis e gases de efeito estufa na atmosfera, riscos às populações humanas, dentre outros (ANDRADE FILHO et al., 2017; SOLER; ÚBEDA, 2018; STEPHENS et al., 2018).

Mesmo adotando práticas protecionistas, todos os anos, extensas áreas florestais são queimadas pelo mundo inteiro (SOARES; BATISTA; TETTO, 2017). Objetivando encontrar técnicas de prevenção e/ou combate aos incêndios florestais, 
várias alternativas foram desenvolvidas, com destaque específico nesse caso, para os produtos químicos retardadores e/ou supressores de fogo (COUTO-VÁZQUEZ; GARCÍA-MARCO; GONZÁLEZ-PRIETO, 2011; CANZIAN et al., 2016; MARSHALL; WALLER; LEKBERG, 2016; PLUCINSKI; SULLIVAN; HURLEY, 2017).

Esses produtos químicos são fornecidos em forma líquida ou em pó, destinados ao combate de incêndios, conforme suas classificações e especificações técnicas recomendadas para aplicação (U.S. FOREST SERVICE, 2015). Em suma, são classificados em duas categorias: retardantes de longo ou de curto prazo (LIODAKIS et al., 2013), sendo que os retardantes de longo prazo são compostos por sais inorgânicos (sulfatos e fosfatos de amônio), e se caracterizam por deixar resíduos dos agentes inibidores da ignição sobre o material combustível, que inibem a combustão mesmo após a evaporação da água. Já, os retardantes de curto prazo são divididos em duas classes: as espumas, que são produtos compostos por surfactantes; e os géis, compostos por polímeros superabsorventes hidrofílicos com capacidade de absorção de até 700 vezes a sua massa em água; e se caracterizam por reduzir a tensão superficial e aumentar a viscosidade e aderência da água, retendo mais umidade no material combustível, contudo perdem a eficiência após a evaporação da matriz aquosa (LIODAKIS et al., 2008; 2013; RAKOWSKA et al., 2014; BARREIRO et al., 2016; MICHALOPOULOS et al., 2016; PLUCINSKI; SULLIVAN; HURLEY, 2017).

Esses produtos têm sido bem aceitos e considerados uma importante e eficiente ferramenta no combate aos incêndios florestais por aplicações aéreas e terrestres (BATISTA et al., 2008; MACHADO FILHO et al., 2012; LIODAKIS et al., 2013; RAKOWSKA et al., 2014; PLUCINSKI; SULLIVAN; HURLEY, 2017). Embora os retardantes de fogo sejam comumente utilizados, são poucas as informações disponíveis sobre seus potenciais impactos ecológicos, de modo que seus efeitos sobre os organismos e ecossistemas ainda precisam ser melhor compreendidos (SONG et al., 2014; BARREIRO et al., 2016), principalmente porque esses produtos geralmente são aplicados em áreas naturais 
ambientalmente sensíveis, e locais não queimados inevitavelmente acabam recebendo parte desses compostos (BASANTA et al., 2002; BARREIRO et al., 2016).

No Brasil, a utilização de retardantes de fogo ainda é incipiente (MACHADO FILHO et al., 2012), todavia esses produtos estão disponíveis comercialmente, o que desperta preocupações devido a inexistência de legislação para regulamentação do seu uso no país (IBAMA, 2018), aliado ainda ao pouco conhecimento sobre seus potenciais efeitos ambientais. Assim, estudos que avaliem os potenciais impactos dos retardantes de fogo sobre os ecossistemas e organismos para as condições brasileiras são necessários.

Alguns estudos alertaram para determinados impactos decorrentes do uso de retardantes de fogo, tanto de longo quanto de curto prazos, como a redução da germinação de sementes no centro-leste da Espanha (LUNA et al., 2007) e na Coréia (SONG et al., 2014); alterações na composição de comunidades de plantas nos Estados Unidos (BESAW et al., 2011); alterações de produtividade de plantas, nutrientes do solo e interações solo-planta na Espanha (COUTO-VÁZQUEZ; GARCÍA-MARCO; GONZÁLEZPRIETO, 2011) e nos Estados Unidos (MARSHALL; WALLER; LEKBERG, 2016), dentre outros.

No Brasil, existem poucos estudos investigando os efeitos dos retardantes de fogo sobre os organismos e o meio ambiente (XIMENES et al., 2021). As pesquisas sobre o uso desses produtos no país têm como foco a eficiência na extinção do incêndio propriamente dita. Portanto, estudos que abordem essa questão podem contribuir para o conhecimento dos riscos associados ao uso dos retardantes, bem como para a formulação de legislação para regulamentação dessa classe de produtos em território brasileiro. Assim, objetivou-se avaliar o efeito de diferentes concentrações de dois retardantes de fogo comerciais e de um polímero hidrorretentor (retardante alternativo) sobre a germinação de sementes de quatro espécies florestais tropicais. 


\section{MATERIAL E MÉTODO}

\subsection{Caracterização da região e das sementes das espécies avaliadas}

Para a realização desta pesquisa foram coletadas sementes de Enterolobium schomburgkii (Benth.) Benth., Handroanthus impetiginosus (Mart. ex DC.) Mattos, Schizolobium parahyba var. amazonicum (Huber ex Ducke) Barneby e Tabebuia roseoalba (Ridl.) Sandwith (daqui em diante referidas pelos nomes populares: faveira, ipê-rosa, paricá e ipê-branco, respectivamente) em árvores da arborização urbana do município de Sinop, MT. As sementes foram coletadas em 2017 e as árvores matrizes foram selecionadas de acordo com as recomendações de Davide e Silva (2008) (Tabela 1). O clima da região é do tipo Aw (tropical quente e úmido) segundo a classificação climática de Köppen, com duas estações bem definidas: seca (maio a setembro) e chuvosa (outubro a abril), a temperatura média mensal varia de 24,0 a $27,0^{\circ} \mathrm{C}$ e a precipitação anual em torno de $1970 \mathrm{~mm}$.

Tabela 1 - Localização e caracterização dendrométrica das árvores matrizes selecionadas para coleta de sementes em Sinop - MT, 2017

\begin{tabular}{|c|c|c|c|c|c|}
\hline \multicolumn{6}{|c|}{ Localização das árvores matrizes } \\
\hline \multirow{2}{*}{$\begin{array}{c}\text { Matriz } \\
\text { (espécie) }\end{array}$} & \multirow{2}{*}{$\mathbf{N}$} & \multicolumn{2}{|c|}{ Coordenadas geográficas ${ }^{(1)}$} & Altitude & Dist. máx. \\
\hline & & Latitude & Longitude & \multicolumn{2}{|c|}{ (m) } \\
\hline Enterolobium schomburgkii & 7 & $\begin{array}{l}11^{\circ} 51^{\prime} 31,4^{\prime \prime} \mathrm{S} \\
11^{\circ} 51^{\prime} 38,0^{\prime \prime} \mathrm{S}\end{array}$ & $\begin{array}{l}55^{\circ} 32^{\prime} 49,9^{\prime \prime} \mathrm{O} \\
55^{\circ} 28^{\prime} 49,1^{\prime \prime} \mathrm{O}\end{array}$ & 374,4 & 7289,2 \\
\hline Handroanthus impetiginosus & 12 & $\begin{array}{l}11^{\circ} 51^{\prime} 02,2^{\prime \prime S} \\
11^{\circ} 51^{\prime} 39,4^{\prime \prime S}\end{array}$ & $\begin{array}{l}55^{\circ} 31^{\prime} 30,9^{\prime \prime} \mathrm{O} \\
55^{\circ} 28^{\prime} 45,1^{\prime \prime} \mathrm{O}\end{array}$ & 373,4 & 5147,3 \\
\hline $\begin{array}{l}\text { Schizolobium parahyba var. } \\
\text { amazonicum }\end{array}$ & 5 & $\begin{array}{l}11^{\circ} 50^{\prime} 48,4^{\prime \prime} \mathrm{S} \\
11^{\circ} 51^{\prime} 04,9^{\prime \prime} \mathrm{S}\end{array}$ & $\begin{array}{l}55^{\circ} 31^{\prime} 30,4^{\prime \prime O} \\
55^{\circ} 31^{\prime} 17,1^{\prime \prime} \mathrm{O}\end{array}$ & 367,4 & 649,6 \\
\hline Tabebuia roseoalba & 12 & $\begin{array}{l}11^{\circ} 49^{\prime} 49,0^{\prime \prime} \mathrm{S} \\
11^{\circ} 51^{\prime} 18,1^{\prime \prime S}\end{array}$ & $\begin{array}{l}55^{\circ} 29^{\prime} 14,6^{\prime \prime O} \\
55^{\circ} 29^{\prime} 37,6^{\prime \prime} \mathrm{O}\end{array}$ & 373,4 & 2826,7 \\
\hline \multicolumn{6}{|c|}{ Variáveis dendrométricas das árvores matrizes $^{(2)}$} \\
\hline \multirow{2}{*}{\multicolumn{2}{|c|}{ Matriz (espécie) }} & Alt $_{\mathrm{T}}$ & Alt $_{c}$ & \multirow{2}{*}{ DAP $(\mathrm{cm})$} & \multirow{2}{*}{ Dc (m) } \\
\hline & & \multicolumn{2}{|c|}{ (m) } & & \\
\hline Enterolobium schomburgkii & & 14,18 & 1,85 & 69,15 & 15,66 \\
\hline Handroanthus impetiginosus & & 12,28 & 2,22 & 34,64 & 9,64 \\
\hline $\begin{array}{l}\text { Schizolobium parahyba var. } \\
\text { amazonicum }\end{array}$ & & 23,97 & 7,27 & 72,79 & 23,37 \\
\hline Tabebuia roseoalba & & 7,72 & 1,68 & 28,01 & 4,82 \\
\hline
\end{tabular}

Fonte: Autores (2019)

Em que: (1) Coordenadas geográficas das árvores mais distantes entre si; (2) Valores médios das árvores matrizes de cada espécie florestal, $\mathrm{N}=$ Número de árvores matrizes, Dist. máx. = Distância máxima

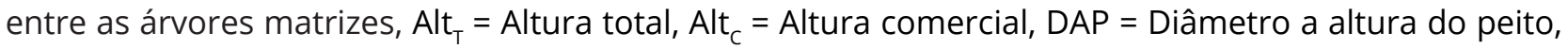
Dc = Diâmetro de copa. 
As sementes de cada espécie florestal foram caracterizadas quanto ao peso de mil sementes e grau de umidade pelo método de estufa a $105 \pm 3^{\circ} \mathrm{C}$ durante 24 h, ambos conforme especificações das Regras para Análise de Sementes (BRASIL, 2009). O beneficiamento foi realizado manualmente e, posteriormente, as sementes foram armazenadas em câmara fria sob temperatura de $12^{\circ} \mathrm{C}$ e umidade relativa de 10\% até a realização dos experimentos. As descrições de tempo armazenamento das sementes antes do ensaio (considerando o tempo de viabilidade de cada espécie), medidas biométricas e características de superfície são apresentadas na Tabela 2.

Tabela 2 - Caracterização das sementes de quatro espécies florestais tropicais coletadas na transição Cerrado-Amazônia, Sinop - MT, 2017

\begin{tabular}{|c|c|c|c|c|c|c|c|}
\hline \multirow[t]{2}{*}{ Espécies } & $\begin{array}{l}\text { Grau de } \\
\text { umidade }\end{array}$ & $\begin{array}{c}\text { Peso } \\
\text { de mil } \\
\text { sementes }\end{array}$ & $\begin{array}{c}\text { Tempo } \\
\text { de } \\
\text { armazenamento }\end{array}$ & Comp. & Larg. & Esp. & \multirow{2}{*}{$\begin{array}{c}\text { Características } \\
\text { de } \\
\text { superfície }\end{array}$} \\
\hline & $(\%)$ & (g) & (dias) & & $(\mathrm{mm})$ & & \\
\hline $\begin{array}{l}\text { Enterolobium } \\
\text { schomburgkii }\end{array}$ & 7,80 & 96,8035 & 196 & 8,81 & 6,23 & 3,51 & TDI e TL \\
\hline $\begin{array}{l}\text { Handroanthus } \\
\text { impetiginosus }\end{array}$ & 7,98 & 27,2696 & 38 & 12,07 & 7,0 & 0,68 & TF e TP \\
\hline $\begin{array}{l}\text { Schizolobium } \\
\text { parahyba var. } \\
\text { amazonicum }\end{array}$ & 5,73 & 804,2721 & 154 & 21,07 & 13,58 & 3,49 & TDI e TL \\
\hline $\begin{array}{l}\text { Tabebuia } \\
\text { roseoalba }\end{array}$ & 7,84 & 12,3514 & 11 & 9,42 & 6,85 & 0,59 & TF e TP \\
\hline
\end{tabular}

Fonte: Autores (2019)

Em que: Comp. = comprimento; Larg. = largura; Esp. = espessura das sementes; $T$ TDI = tegumento duro e impermeável; $T L$ = textura lisa; TF = tegumento flexível; TP = textura papirácea.

\subsection{Testes de germinação}

Os testes de germinação foram conduzidos entre setembro de 2017 e março de 2018. Antes da instalação dos experimentos, as sementes foram submetidas a tratamentos pré-germinativos para superação de dormência e/ou aceleração do 
processo germinativo, que consistiram na escarificação química do tegumento com imersão das sementes de faveira em ácido sulfúrico $\left(\mathrm{H}_{2} \mathrm{SO}_{4} 95 \%\right)$ por 20 minutos; imersão das sementes de paricá em água a $100^{\circ} \mathrm{C}$ por dois minutos e semeadura após 24 horas na água; e remoção das alas para as espécies ipê-branco e ipê-rosa. Posteriormente, foram desinfestadas em solução de hipoclorito de sódio a $2 \%$ por cinco minutos, em seguida lavadas em água destilada.

Destaca-se que não foram realizadas comparações entre os produtos, pois estes apresentam diferentes recomendações comerciais e composições químicas. O delineamento experimental utilizado foi o inteiramente casualizado, com os tratamentos estabelecidos pelas concentrações (diluídas em água destilada) dos seguintes produtos retardantes de fogo de curto prazo: i) Phos-Chek WD881®, nas concentrações de 0,0 (controle), 0,1;0,3;0,6;0,8 e 1,0 mL L-1; ii) Hold Fire ${ }^{\circledR}$, nas concentrações de 0,0 (controle), 0,$7 ; 0,9 ; 1,1 ; 1,3$ e $1,5 \mathrm{~mL} \mathrm{~L}^{-1}$; e do iii) polímero hidrorretentor (Nutrigel ${ }^{\circledR}$ ), nas concentrações de 0,00 (controle), 0,10; 0,25; 0,50; 0,75 e 1,0 $\mathrm{g} \mathrm{L}^{-1} ;$ e, somente água destilada no tratamento controle.

O polímero hidrorretentor empregado foi o da marca Nutrigel ${ }^{\circledR}$, desenvolvido e regulamentado no Brasil como condicionador hídrico do solo. A sua utilização como "retardante do fogo" pode ser considerada como uma alternativa viável em função do baixo custo e pelo fato de ser um produto biodegradável. Esse produto, apresenta

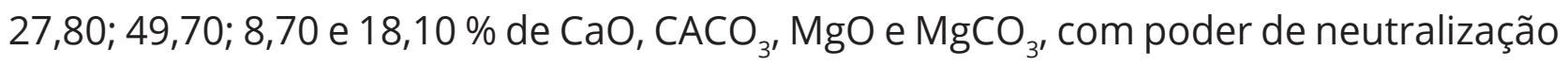
de 67,50\% (perfazendo em classificação semelhante ao calcário dolomítico) e polímeros sintéticos de poliacrilamida. Como não existe recomendação do produto para essa finalidade, as concentrações avaliadas neste trabalho foram definidas pela avaliação em campo realizadas por Lima et al. (2020 a,b).

Para as avaliações de germinação e de vigor das sementes foram utilizadas quatro repetições de 100 sementes para o ipê-branco e ipê-rosa; quatro repetições de 30 sementes para faveira e quatro repetições de 25 sementes para o paricá, para cada tratamento supracitado. E para a análise do vigor de plântulas, foram utilizadas quatro repetições de 25 sementes para todas as espécies. 
As sementes foram acondicionadas sobre papel germitest em caixas plásticas de germinação $(25,1$ x 21,5 x 8,2 cm), umedecido com as soluções de cada tratamento em quantidade ( $\mathrm{mL}$ ) equivalente a três vezes o peso do papel (BRASIL, 2009). As caixas plásticas foram mantidas em câmaras de germinação à temperatura constante de $30^{\circ} \mathrm{C}$ e fotoperíodo de 12 horas, com iluminação por lâmpadas fluorescentes (2500 lux). As variáveis avaliadas foram: primeira contagem de germinação (PCG), conduzida juntamente com o teste de germinação e realizada aos sete dias; porcentagem de germinação final, realizada aos 14 dias, em que foram consideradas germinadas as sementes que originaram plântulas normais em ambas (BRASIL, 2009). Índice de velocidade de germinação (IVG), obtido através do número de sementes germinadas diariamente, as quais foram consideradas germinadas quando apresentavam no mínimo 2,0 mm de raiz primária, e calculado segundo a fórmula proposta por Maguire (1962). E tempo médio de germinação (TMG), obtido por meio das contagens diárias das sementes germinadas até o décimo quarto dia.

As contagens de sementes germinadas foram realizadas diariamente a partir do dia seguinte da instalação de cada experimento, pelo período de 14 dias para cada espécie. A primeira contagem de plântulas normais foi realizada aos sete dias, com avaliação final aos 14 dias, incluindo a contabilização de plântulas anormais e sementes não germinadas (mortas e duras) (BRASIL, 2009).

\subsection{Análise estatística}

Os dados de germinação foram submetidos ao teste de normalidade de ShapiroWilk $(p \leq 0,05)$ e posteriormente à análise de variância pelo teste F. Quando significativas, as análises de regressão (linear ou polinomial) foram obtidas para as concentrações de cada produto individualmente por espécie, ao nível de 5\% de probabilidade. Quando necessário, os dados foram transformados em [raiz(x/100)]. Para os dados de vigor de plântulas realizou-se análise descritiva como forma de representação dos resultados. 


\section{RESULTADOS E DISCUSSÃO}

\subsection{Retardante Phos-Check WD881}

O aumento das concentrações de Phos-Chek WD881 influenciou significativamente apenas o IVG do ipê-branco e do ipê-rosa (Figura 1B). Essas espécies apresentaram reduções lineares do IVG, sendo estas mais acentuadas a partir da concentração 0,6 mL L-1 , atingindo reduções de 77,1\% (ipê-branco) e 78,9\% (ipê-rosa), na concentração de $1,0 \mathrm{~mL} \mathrm{~L}^{-1}$, em relação ao controle $\left(0,0 \mathrm{~mL} \mathrm{~L}^{-1}\right)$.

A PCG também decresceu em função do aumento das concentrações do retardante para o ipê-branco, ipê-rosa e paricá, sendo estas reduções de 82,0; 81,0 e 16,0\% respectivamente, ambas na concentração $1,0 \mathrm{~mL} \mathrm{~L}^{-1}$, em relação ao controle $\left(0,0 \mathrm{~mL} \mathrm{~L}^{-1}\right)$ (Figura 1C). Por outro lado, para a faveira não houve influência do aumento das concentrações de Phos-Chek WD881 no percentual de germinação na primeira contagem. A germinação e o TMG não foram influenciados significativamente pelo aumento das concentrações de Phos-Chek WD881 para nenhuma das espécies florestais avaliadas (Figuras 1A e D).

Apesar de alguns efeitos do uso de produtos químicos de combate a incêndios florestais terem sido relatados para alguns organismos e ambientes (BESAW et al., 2011; SONG et al., 2014; BARREIRO et al., 2016; MARSHALL; WALLER; LEKBERG, 2016), as informações sobre os efeitos em plantas são escassas para se chegar a um consenso sobre a possível toxidade dos retardantes e seu mecanismo, principalmente quanto ao processo de germinação de sementes. Mais escassos ainda são os estudos avaliando os efeitos dos retardantes de curta duração, visto que a maioria dos estudos realizados e publicados sobre o tema investigaram os efeitos dos retardantes de longa duração.

Analisando o efeito de soluções pura e diluída a 1,0\% de Phos-Chek WD881, Song et al. (2014) constataram redução significativa na germinação de sementes de Pinus densiflora, Pinus rigida e Brassica campestris para ambos tratamentos. Esses autores também verificaram diferenças na germinação entre as espécies vegetais 
e afirmaram que, apesar da toxidade do retardante ter diminuído à medida que foi diluído, a germinação foi inibida.

Figura 1 - Variáveis de germinação de espécies florestais tropicais em diferentes concentrações de Phos-Chek WD881. Porcentagem de germinação aos 14 dias após a semeadura (A), índice de velocidade de germinação - IVG (B), primeira contagem de germinação - PCG, realizada aos sete dias após a semeadura (C) e tempo médio de germinação - TMG (D)
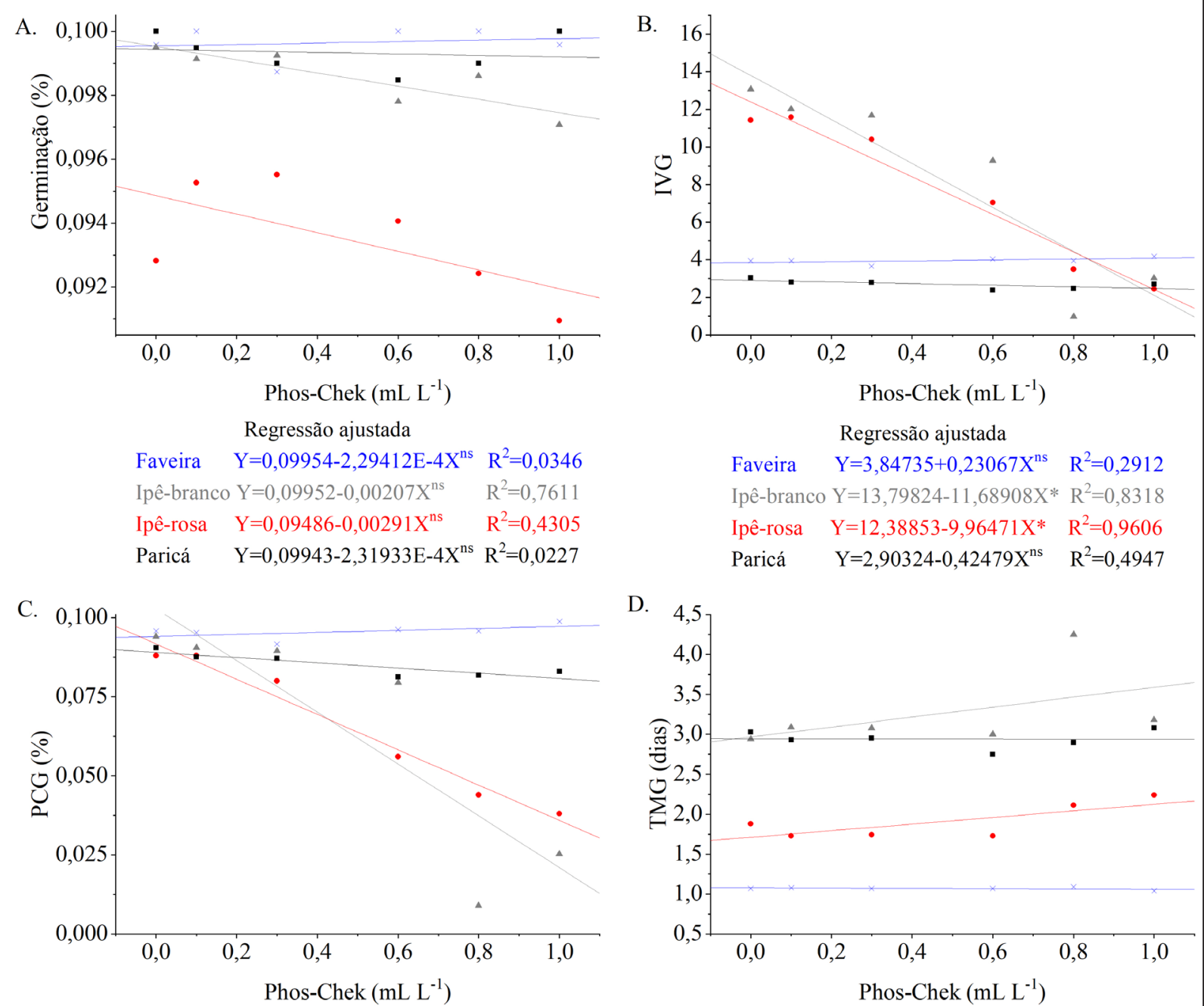

D.

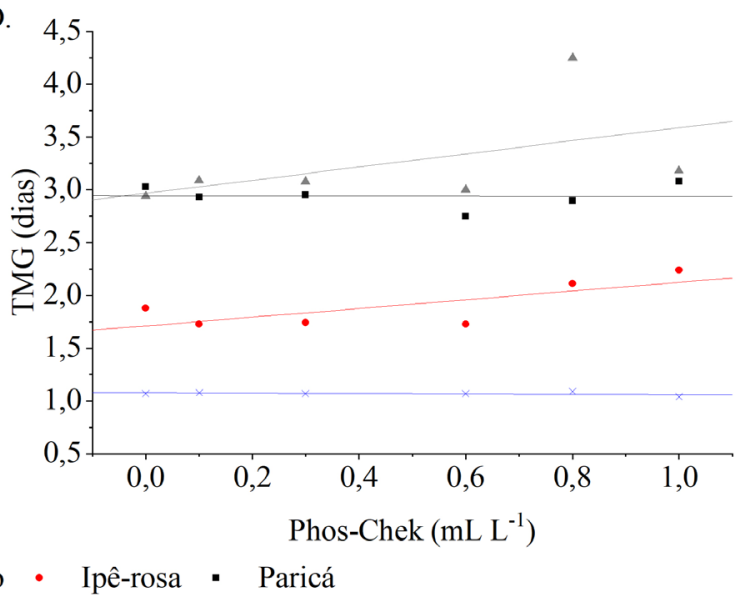

$\begin{array}{lcc} & \text { Regressão ajustada } & \\ \text { Faveira } & \mathrm{Y}=0,09407-0,00316 \mathrm{X}^{\mathrm{ns}} & \mathrm{R}^{2}=0,3078 \\ \text { Ipê-branco } \mathrm{Y}=0,10282-0,0818 \mathrm{X}^{*} & \mathrm{R}^{2}=0,7571 \\ \text { Ipê-rosa } & \mathrm{Y}=0,09171-0,0558 \mathrm{X}^{*} & \mathrm{R}^{2}=0,9758 \\ \text { Paricá } & \mathrm{Y}=0,08904-0,00829 \mathrm{X}^{*} & \mathrm{R}^{2}=0,7693\end{array}$

Regressão ajustada

Faveira $\quad \mathrm{Y}=1,07765-0,01639 \mathrm{X}^{\mathrm{ns}} \quad \mathrm{R}^{2}=0,1522$

Ipê-branco $Y=2,96588+0,62311 X^{n s} R^{2}=0,2529$

Ipê-rosa $\quad \mathrm{Y}=1,71076+0,41336 \mathrm{X}^{\mathrm{ns}} \mathrm{R}^{2}=0,5531$

Paricá $\quad \mathrm{Y}=2,94235-0,00504 \mathrm{X}^{\mathrm{ns}} \mathrm{R}^{2}=0,0003$

Fonte: Autores (2019)

Em que: Dados de germinação (\%) e PCG foram transformados em [raiz(x/100)]. * significativo ao nível de 5\% de probabilidade; ns não significativo. 
O padrão de vigor das plântulas variou entre as espécies em reposta às concentrações crescentes de Phos-Chek WD881 (Figura 2), pois o aumento das concentrações do retardante causou decréscimos expressivos na quantidade de plântulas normais de ipê-branco, ipê-rosa e paricá. As maiores reduções de plântulas normais também foram verificadas a partir de $0,6 \mathrm{~mL} \mathrm{~L}^{-1}$ de Phos-Chek WD881, sendo observados percentuais máximos de 91,0\% (ipê-branco), 68,3\% (ipêrosa) e 30,0\% (paricá) de plântulas classificadas como anormais em concentrações iguais ou superiores a $0,6 \mathrm{~mL} \mathrm{~L}^{-1}$ do produto retardante. A faveira não foi afetada pelas concentrações crescentes do Phos-Chek WD881, sendo, portanto, as variações observadas nas porcentagens de plântulas normais e anormais dependentes apenas dos fatores genéticos e/ou dos lotes de sementes (Figura 2).

Figura 2 - Percentuais médios de plântulas normais, anormais e sementes não germinadas (sementes mortas e duras) de espécies florestais tropicais em diferentes concentrações de Phos-Chek WD881

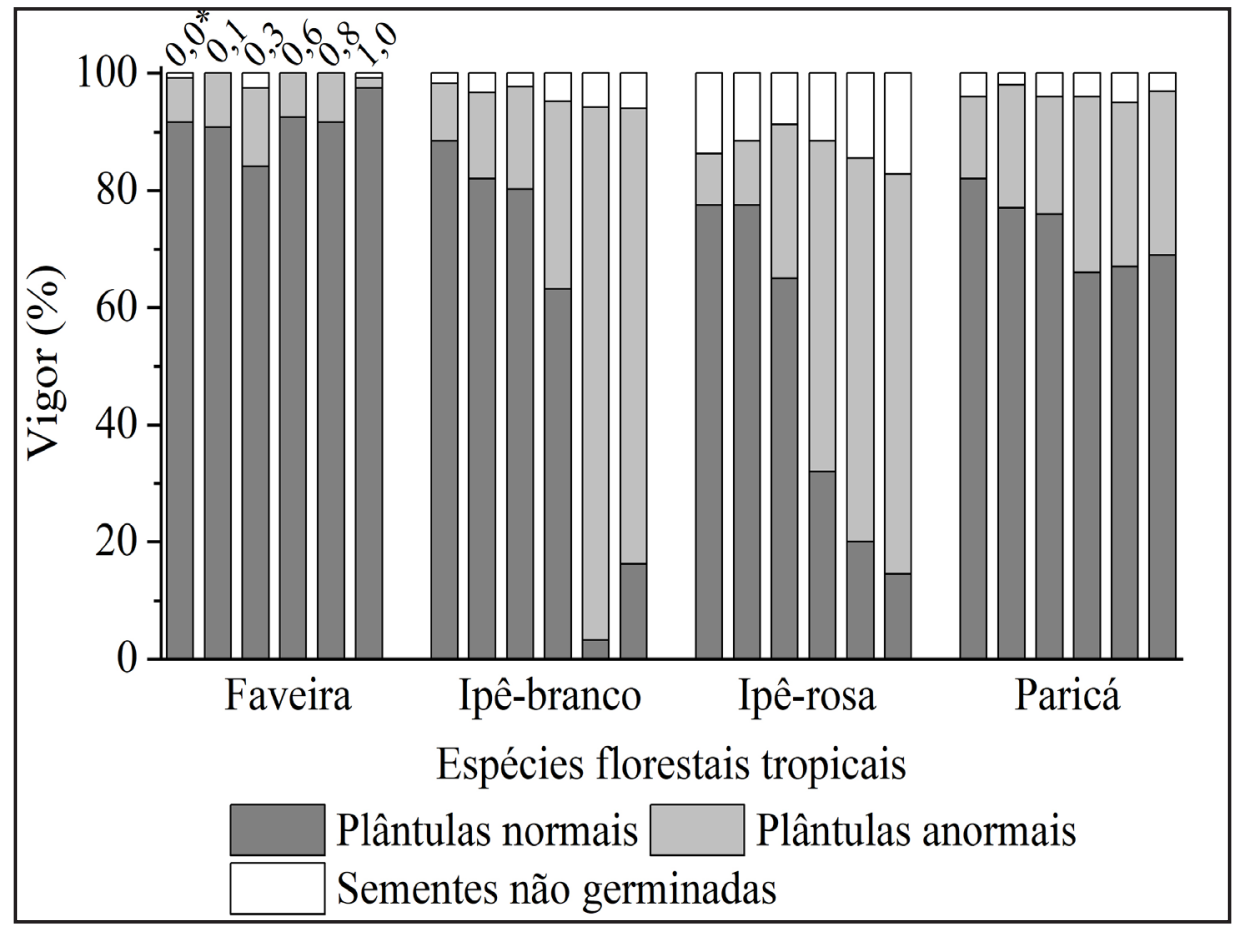

Fonte: Autores (2019)

Em que: *Concentrações do Phos-Chek WD881 para cada espécie. 
A drástica redução na formação de plântulas normais para o ipê-branco, ipêrosa e paricá demonstrou que essas espécies são sensíveis a concentrações $\geq 0,6 \mathrm{~mL}$ L $^{-1}$ de Phos-Chek WD881, pois o estabelecimento dessas plântulas nessas condições foi severamente comprometido, confirmado pelas altas reduções de plântulas normais em relação ao tratamento controle (Figura 2). Isso demonstra que a intensidade dos efeitos em função de aplicações de Phos-Chek WD881 também é variável em função da espécie vegetal, podendo estar relacionada à morfologia das sementes, uma vez que a consistência do tegumento é uma característica que divide as espécies estudadas em dois grupos distintos. Sendo um caracterizado por sementes com tegumento flexível (ipê-branco e ipê-rosa) facilmente permeável e o outro por sementes com tegumento duro e impermeável (faveira e paricá) (Tabela 2).

Song et al. (2014) também encontraram esse padrão de efeito associado à redução da germinação de Brassica campestris e o atribuíram à espessura do revestimento das sementes, pois notaram que Pinus densiflora e Pinus rigida, que apresentavam sementes com tegumentos mais espessos, sofreram menor inibição da germinação. Por outro lado, Hamilton e Buhl (1997) apontaram que a toxidade de espumas supressoras, como o Phos-Chek WD881, pode ser parcialmente decorrente da porção surfactante aniônico da sua composição. Investigando os efeitos de retardantes de fogo em organismos aquáticos, esses mesmos autores verificaram que as espumas Phos-Chek WD881 e Silv-Ex têm uma toxidade muito semelhante e são substancialmente mais tóxicas do que os retardantes de longa duração, além de terem causado maior toxidade para dafnídeos (Daphnia magna) e anfípodes (Hyalellaazteca).

Outro ponto a destacar, é que com a alteração da tensão superficial da água, os surfactantes reduzem a hidrofobicidade dos lipídeos e danificam os componentes lipídicos das membranas celulares, causando uma super-hidratação (CARRASCHI et al., 2012), que pode evoluir para necrose celular pela supressão dos processos metabólicos, em caso de altas concentrações (FOOD AND AGRICULTURE ORGANIZATION OF THE UNITED NATIONS, 1993). Isso pode justificar e explicar as anormalidades verificadas nas plântulas submetidas ao Phos-Chek WD881 (Figura 3) neste estudo. As quais, especialmente os ipês branco e rosa, apresentaram raízes atrofiadas, necrosadas 
e/ou enegrecidas nas porções apicais, com maior severidade com o aumento das concentrações desse retardante, além do não estabelecimento dessas plântulas nas concentrações iguais ou superiores a $0,6 \mathrm{~mL} \mathrm{~L}^{-1}$.

Diante disso, é importante alertar para o fato de que tanto o ipê-branco quanto o ipê-rosa dispersam suas sementes no período da estação seca da região, entre os meses de setembro e outubro, que coincide justamente com a época de maior incidência de incêndios na região do Centro-Norte brasileiro. Fato que requer atenção, pois as sementes dessas espécies são quiescentes e germinam rapidamente após a dispersão, caso as condições ambientais estejam favoráveis, ou seja, o uso do PhosChek WD881 poderia acarretar em efeitos negativos para essas plântulas, caso fossem atingidas por esse produto durante a sua aplicação na realização de aceiros molhados (CANZIAN et al., 2016) ou aplicações acidentais e/ou desnecessárias.

Figura 3 - Plântulas dos tratamentos controles (imagens superiores) e a 1,0 mL L-1 de Phos-Chek WD881 (imagens inferiores), faveira (Enterolobium schomburgkii) (A e E), ipê-rosa (Handroanthus impetiginosus) (B e F), ipê-branco (Tabebuia roseoalba) (C e G) e paricá (Schizolobium parahyba var. amazonicum) (D e H), ambas aos 14 dias após a semeadura, Sinop - MT, 2018

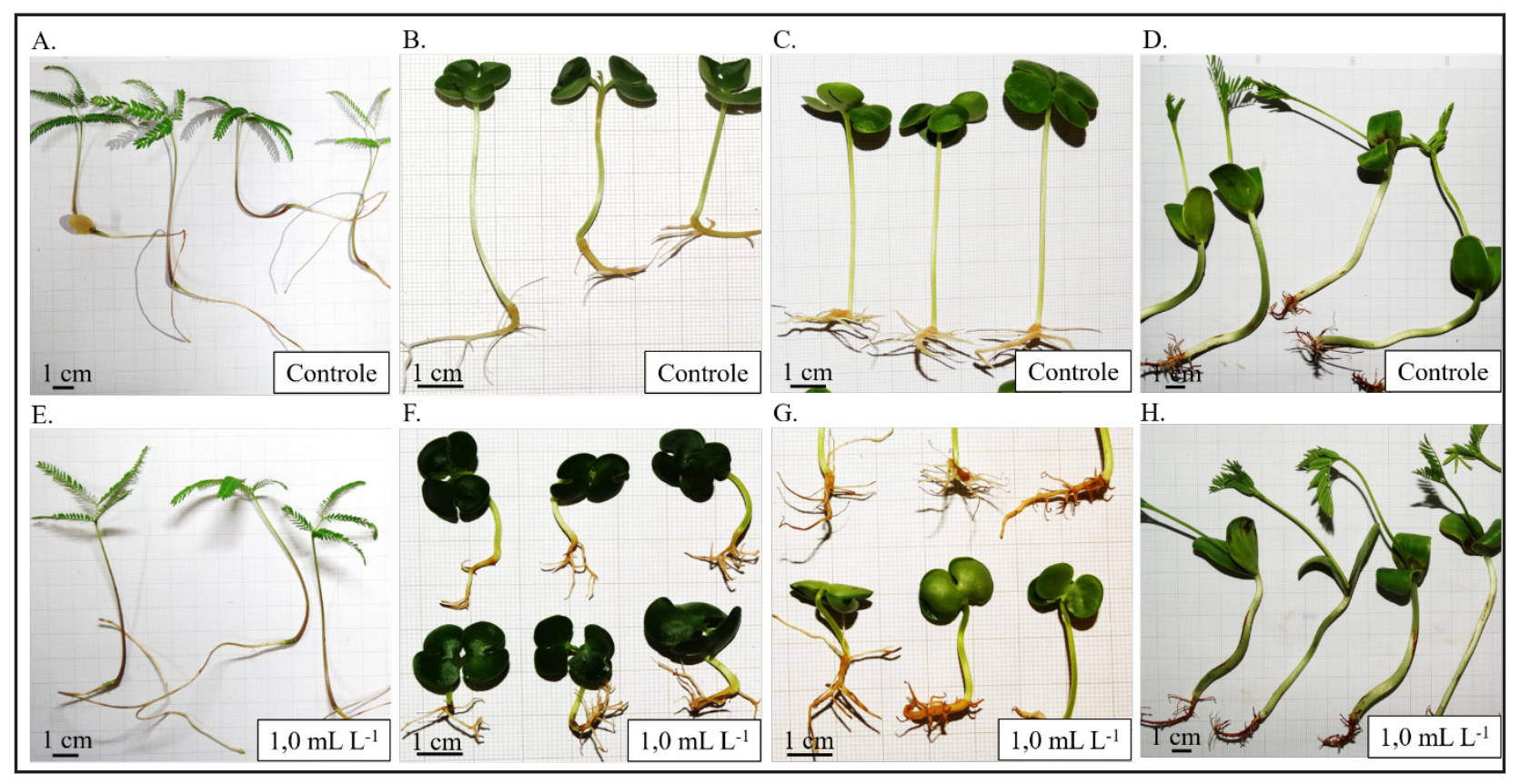

Fonte: Autores (2019) 


\subsection{Retardante Hold Fire}

O aumento das concentrações de Hold Fire influenciou a germinação das sementes do ipê-rosa, que expressou máxima porcentagem de germinação (97\%) na concentração de 1,1 mL L-1 (Figura 4A). Foram observados incrementos de 10,3\% $\left(1,1 \mathrm{~mL} \mathrm{~L}^{-1}\right)$ e 7,4\% (1,5 mL L-1) na germinação das sementes dessa espécie, enquanto que nas demais espécies não se observaram efeitos significativos na germinação em função desse retardante. O IVG foi influenciado significativamente apenas para o ipêbranco, com máxima velocidade de germinação estimada na concentração de 0,68 $m L L^{-1}$ de Hold Fire (Figura 4B). Sob concentrações crescentes de Hold Fire não foram verificados efeitos significativos nos percentuais da PCG e do TMG até o nível de 1,5 $\mathrm{mL} \mathrm{L}{ }^{-1}$ para nenhuma das espécies avaliadas (Figuras 4C e 4D).

As únicas informações disponibilizadas, mas não publicadas, sobre a toxicidade do retardante de incêndios Hold Fire são de análises químicas realizadas por laboratórios contratados pelo fabricante, e realizadas com os organismos aquáticos Daphnia magna, Desmodesmus subspicatus e Vibrio fischeri. Assim, a presente pesquisa trata-se de um estudo inédito que contribui para o conhecimento e melhor entendimento dos efeitos desse retardante de incêndio de curta duração sobre as plantas.

Embora o Hold Fire seja considerado biodegradável, de composição orgânica natural e com biodegradação de $80 \%$ em até 30 dias (SILVA FILHO, 2017), o uso desse produto em ambientes naturais deve ser feito com cautela, pois seus efeitos não são completamente conhecidos, e a variação no padrão de germinação aqui verificada indica que as implicações desse retardante sobre as plantas precisam ser investigadas. Isto porque alterações no padrão de germinação poderiam acarretar em mudanças na composição de espécies, no favorecimento da colonização de novos locais por espécies invasoras, ou ainda tornar vulneráveis as sementes que estejam nos bancos de sementes do solo após exposição aos retardantes (BESAW et al., 2011; SONG et al., 2014). Essa cautela se torna ainda mais necessária pelo desconhecimento sobre a mobilidade desse produto no solo, assim como por outros possíveis efeitos ambientais. 
Figura 4 - Variáveis de germinação de espécies florestais tropicais em diferentes concentrações de Hold Fire. Porcentagem de germinação aos 14 dias após a semeadura (A), índice de velocidade de germinação - IVG (B), primeira contagem de germinação - PCG, realizada aos sete dias após a semeadura (C) e tempo médio de germinação TMG (D)

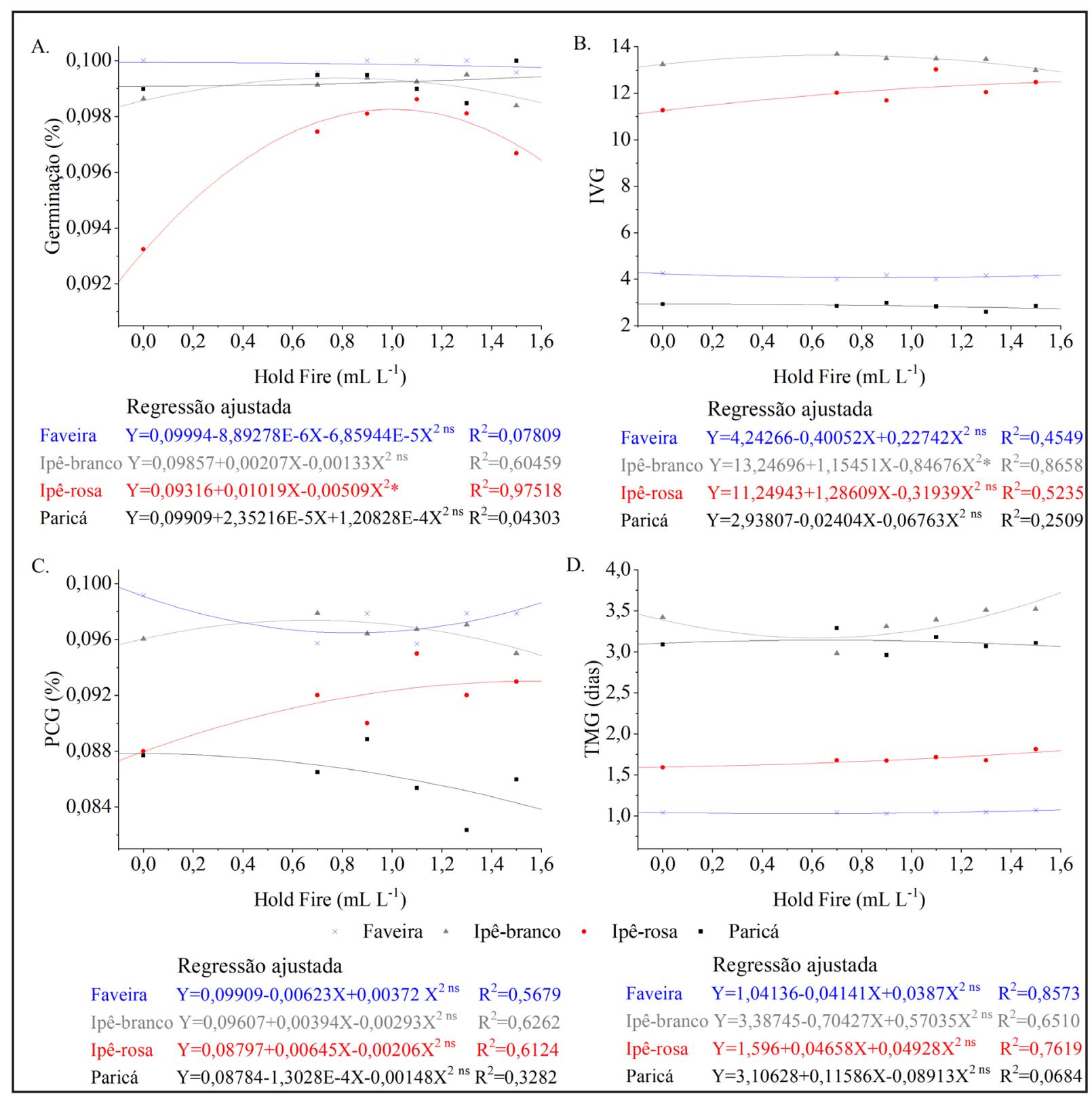

Fonte: Autores (2019)

Em que: Dados de germinação (\%) e PCG foram transformados em [raiz(x/100)]. * significativo ao nível de $5 \%$ de probabilidade; ns não significativo. 
O aumento das concentrações de Hold Fire não causou variações expressivas no vigor de plântulas das espécies florestais analisadas, que apresentaram 98,0\% (0,0 mL L-1 - faveira), 96,0\% (0,7 mL L-1 - ipê-branco), 91,0\% (1,1 mL L-1 - ipê-rosa) e 79,0\% (0,9 mL L-1 - paricá) de plântulas normais (Figura 5). A maior taxa de sementes não germinadas (14,0\%), observada para o ipê-rosa em $0,0 \mathrm{~mL} \mathrm{~L}^{-1}$, não foi associada como efeito do retardante, devido a ocorrência de fungos nesse tratamento.

Apesar do Hold Fire não ter mostrado evidência de fitotoxidade às espécies florestais tropicais testadas em laboratório, entendemos que seu real impacto ecológico nos ecossistemas naturais precisa ser avaliado. Uma vez que até o momento isso não foi investigado, e seus efeitos sobre as plantas e ambientes naturais são pouco conhecidos.

Figura 5 - Percentuais médios de plântulas normais, anormais e sementes não germinadas (sementes mortas e duras) de espécies florestais tropicais em diferentes concentrações de Hold Fire

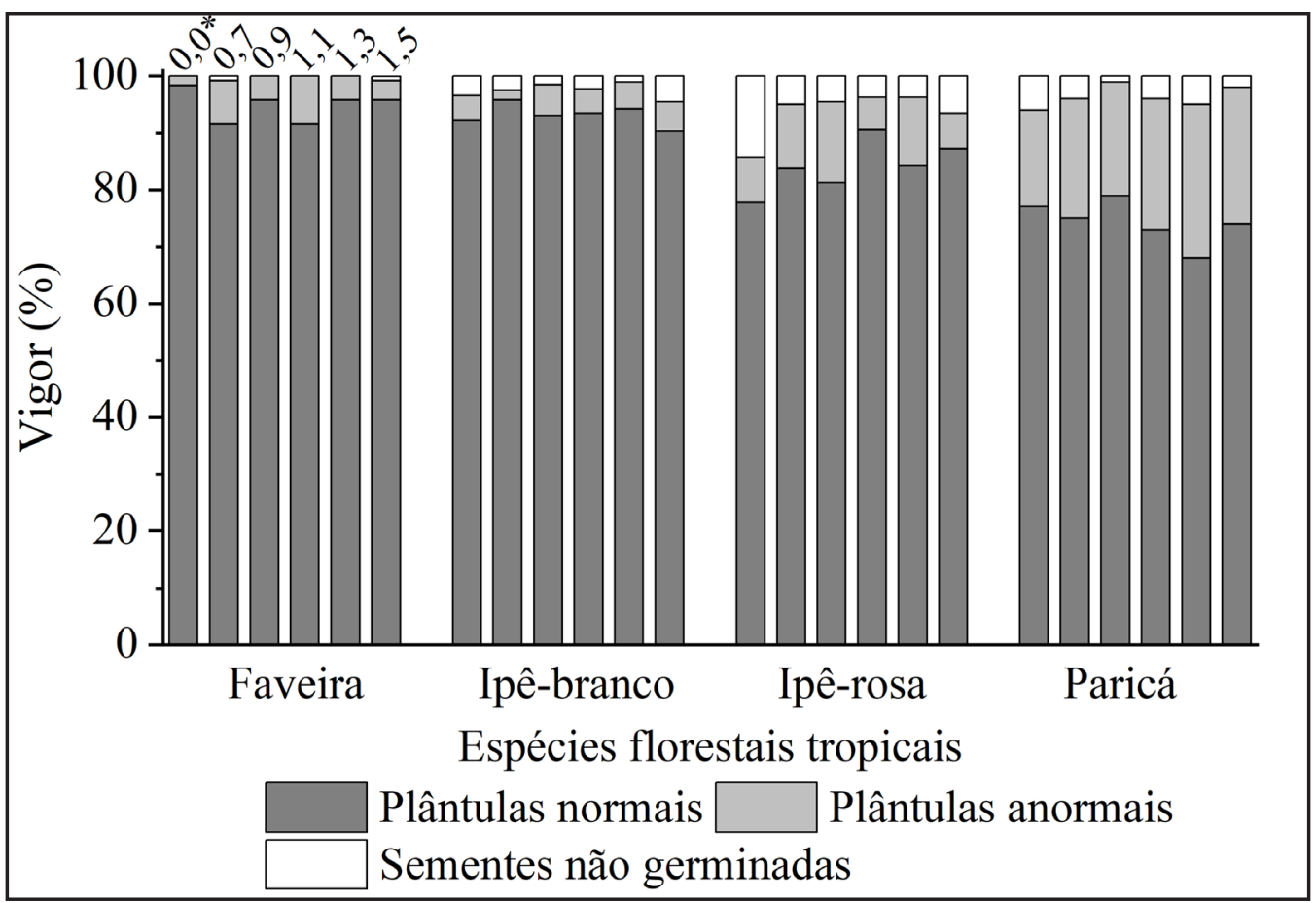

Fonte: Autores (2019)

Em que: *Concentrações do Hold Fire para cada espécie. 


\subsection{Retardante polímero hidrorretentor}

Quanto ao polímero hidrorretentor, independentementeda espécie, não houve efeito significativo para nenhuma variável de germinação em função do aumento das concentrações desse produto (Figura 6). De acordo com Pazderu e Koudela (2013), somente é possível detectar os efeitos dos hidrogéis em sementes que possuem germinação rápida. Apesar das espécies florestais examinadas neste estudo (ipê-branco e ipê-rosa) atenderem a esse requisito, o polímero hidrorretentor não influenciou nos processos germinativos das espécies florestais tropicais avaliadas.

O aumento na concentração do polímero hidrorretentor causou redução de 14,3\% de plântulas normais para o paricá em 0,10 $\mathrm{g} \mathrm{L}^{-1}$, bem como os menores valores dessa variável nas demais concentrações, em relação ao tratamento controle (Figura 7). Para as demais espécies florestais avaliadas, a formação de plântulas normais, após 14 dias, foi superior a 92,0\% $\left(0,10 \mathrm{~g} \mathrm{~L}^{-1}\right)$ para a faveira, $89,0 \%\left(0,00 \mathrm{~g} \mathrm{~L}^{-1}\right)$ para o ipêbranco e 83,0\% (0,10 $\left.\mathrm{g} \mathrm{L}^{-1}\right)$ para o ipê-rosa, não apresentando variações expressivas nas demais concentrações (Figura 7).

Esse efeito pode estar relacionado a diferença de potencial hídrico do polímero hidrorretentor e da semente, pois sementes secas possuem um potencial hídrico muito baixo inicialmente em relação ao hidrogel, que é aumentado pela embebição, até que ambos os potenciais se igualem, o que pode influenciar no fluxo de água para dentro da semente (BEWLEY; BLACK, 1994; PAZDERU; KOUDELA, 2013). Nesse caso, o tamanho da semente e a espessura do tegumento podem ter contribuído para as influências observadas para o paricá neste estudo (Tabela 2). Assim, a velocidade de absorção de água pelas sementes pode diminuir com a aplicação de hidrogel, resultando em germinação lenta (PAZDERU; KOUDELA, 2013) ou formação de plântulas anormais. 
Figura 6 - Variáveis de germinação de espécies florestais tropicais em diferentes concentrações de Polímero Hidrorretentor. Porcentagem de germinação aos 14 dias após a semeadura (A), índice de velocidade de germinação - IVG (B), primeira contagem de germinação - PCG realizada aos sete dias após a semeadura (C) e tempo médio de germinação - TMG (D)

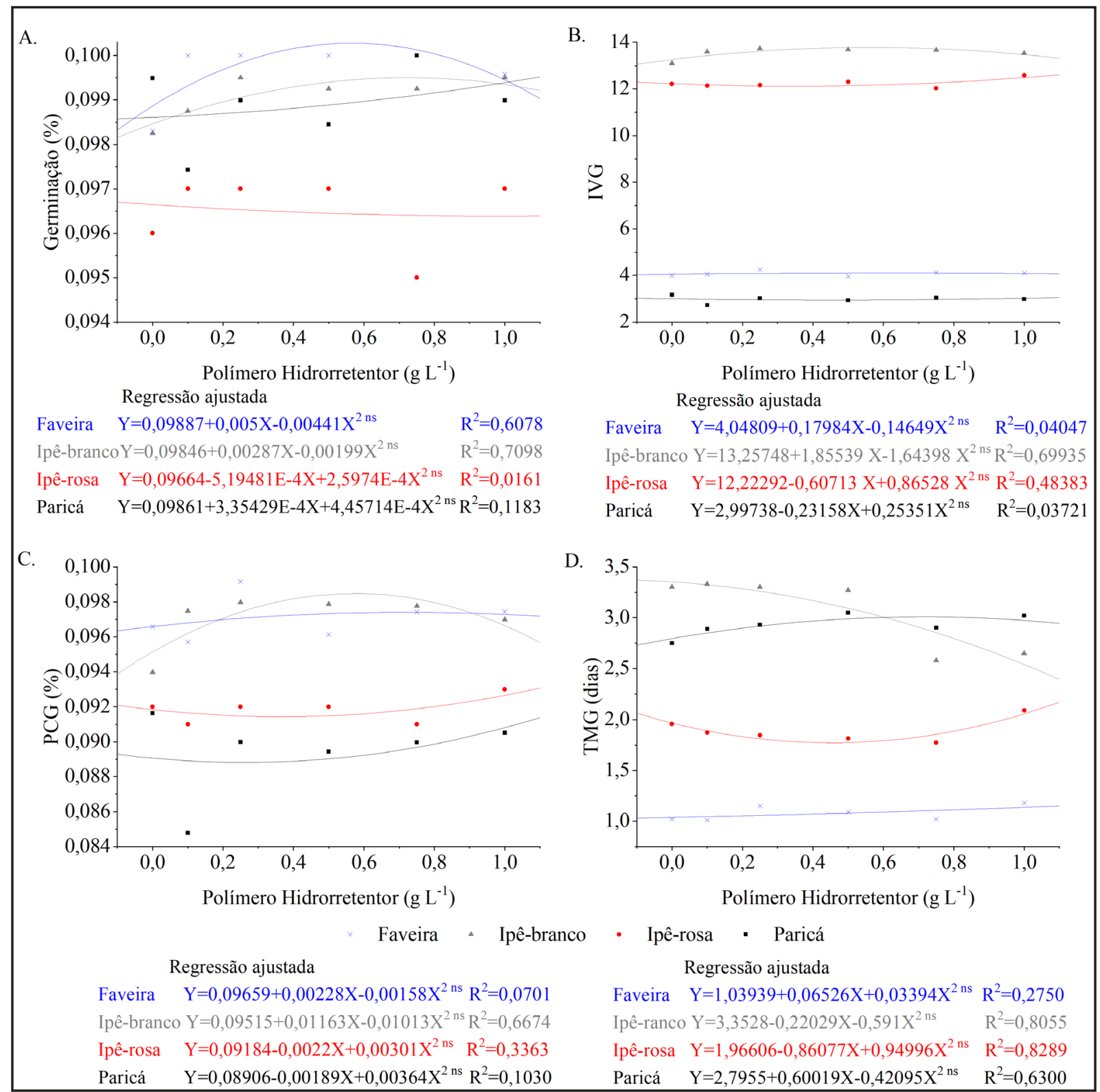

Fonte: Autores (2019)

Em que: Dados de germinação (\%) e PCG foram transformados em [raiz(x/100)]. * significativo ao nível de $5 \%$ de probabilidade. ${ }^{\text {ns }}$ não significativo. 
Ao avaliarem o efeito de um hidrogel na germinação de sementes de colza (Brassica napus), Tang et al. (2014) obtiveram alta taxa de germinação para as sementes submetidas a 2,0\% do produto. Por outro lado, Pazderu e Koudela (2013), ao avaliarem a influência de um hidrogel na germinação de sementes de alface (Lactuca sativa) e cebola (Allium cepa), verificaram que concentrações elevadas do polímero reduziram a germinação de ambas as espécies, sendo que esses autores argumentaram que a influência negativa do hidrogel estava relacionada à dose e também a cultivar, em termos de sensibilidade.

Figura 7 - Percentuais médios de plântulas normais, anormais e sementes não germinadas (sementes mortas e duras) de espécies florestais tropicais em diferentes concentrações de Polímero Hidrorretentor

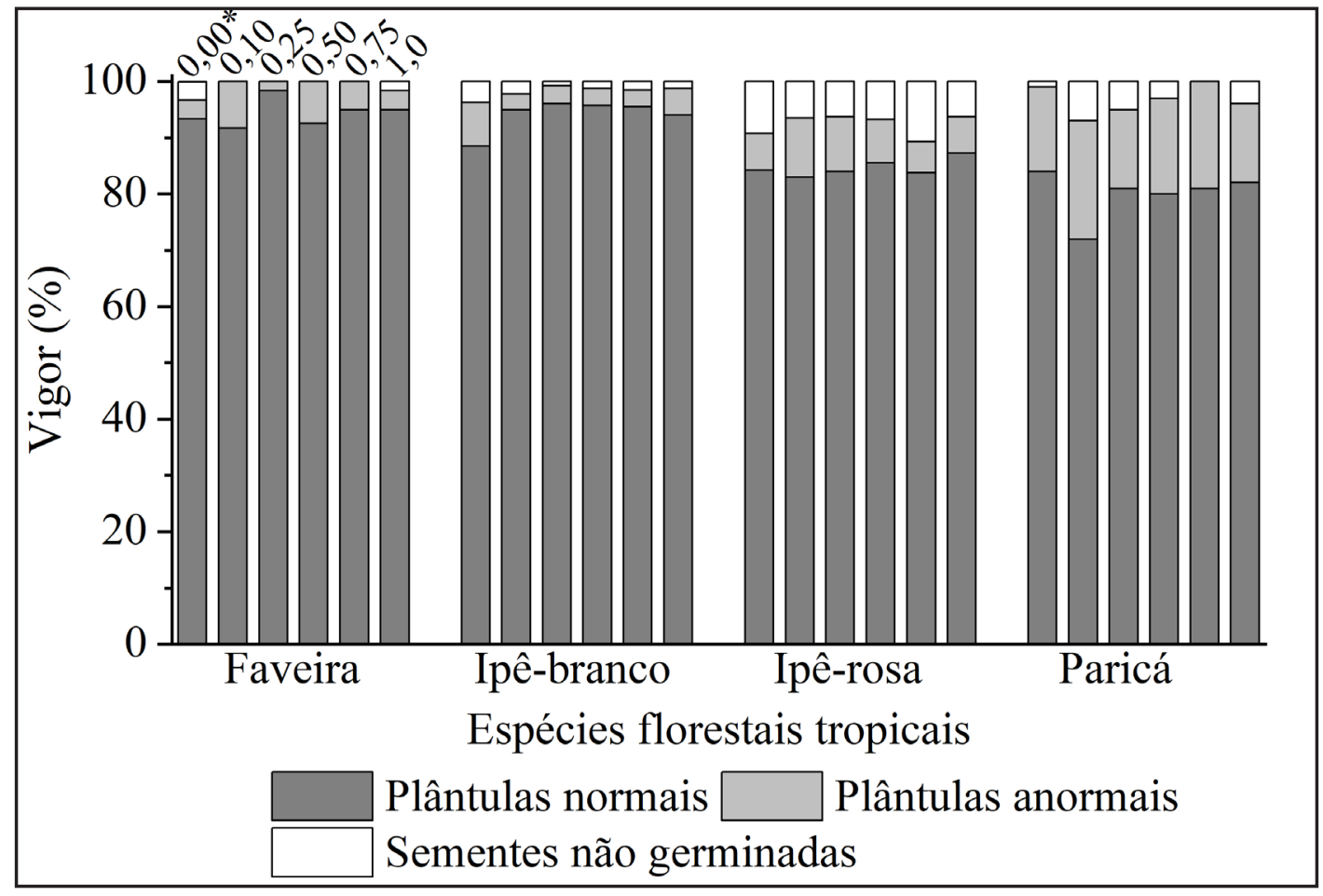

Fonte: Autores (2019)

Em que: *Concentrações do polímero hidrorretentor para cada espécie. 


\section{CONCLUSÕES}

O retardante Phos-Check WD881 afetou negativamente o índice de velocidade de germinação do ipê-branco (Tabebuia roseoalba) e do ipê-rosa (Handroanthus impetiginosus), a primeira contagem de germinação do ipê-branco e do paricá (Schizolobium parahyba var. amazonicum) e o vigor das plântulas de ipê-branco, ipêrosa e paricá.

O retardante de fogo Hold Fire influenciou a porcentagem de germinação final do ipê-rosa e o índice de velocidade de germinação do ipê-branco, mas não comprometeu o vigor das plântulas.

O polímero hidrorretentor não influenciou nas taxas de germinação de nenhuma espécie florestal avaliada, porém pode afetar o vigor das plântulas de paricá.

As espécies ipê-branco e ipê-rosa podem ser consideradas mais sensíveis aos produtos retardantes de fogo, em condições laboratoriais.

Possíveis efeitos fitotóxicos foram identificados para o retardante Phos-Chek WD881 utilizado em concentrações iguais ou superiores a $0,6 \mathrm{~mL} \mathrm{~L}^{-1}$, em condições laboratoriais.

\section{AGRADECIMENTOS}

O presente trabalho foi realizado com apoio da Coordenação de Aperfeiçoamento de Pessoal de Nível Superior - Brasil (CAPES) - Código de Financiamento 001. Ao Sr. José Renato Favaro pela doação do produto comercial "Hold Fire" para o desenvolvimento de experimentos.

\section{REFERÊNCIAS}

ANDRADE FILHO, V. S. et al. Distribuição espacial de queimadas e mortalidade em idosos em região da Amazônia Brasileira, 2001 - 2012.Ciência e Saúde Coletiva, Rio de Janeiro, v. 22, n. 1, p. 245-253, 2017. 
BARREIRO, A. et al. Long-term response of soil microbial communities to fire and fire-fighting chemicals. Biology and Fertility Soils, Berlin, v. 52, p. 963-975, 2016.

BASANTA, M. R. et al. Biochemical properties of forest soils as affected by a fire retardant. Biology and Fertility of Soils, Berlin, v. 36, n. 5, p. 377-383, 2002.

BATISTA, A. C. et al. Avaliação da eficiência de um retardante de longa duração, à base de polifosfatoamônico, em queimas controladas em condições de laboratório. Scientia Forestalis, Piracicaba, v. 36, n. 79, p. 223-229, 2008.

BESAW, L. M. et al. Disturbance, resource pulses and invasion: short-term shifts in competitive effects, not growth responses, favour exotic annuals. Journal of Applied Ecology, Oxford, v. 48, p. 998-1006, 2011.

BEWLEY, J. D.; BLACK, M. Seeds physiology of development and germination. New York: Plenum Press, 1994. 494 p.

BRASIL. Ministério da Agricultura, Pecuária e Abastecimento. Regras para análise de sementes. Brasília, 2009. 399 p.

CANZIAN, W. P. et al. Diferentes concentrações de retardante de fogo em plantios de eucalipto. Nativa, Sinop, v. 4, n. 4, p. 195-198, 2016.

CARRASCHI, S. P. et al. Toxicidade aguda e risco ambiental de surfactantes agrícolas para o guaru Phalloceros caudimaculatus (Pices: Poecilidae). Journal of the Brazilian Society of Ecotoxicology, Itajaí, v. 7, n. 1, p. 27-32, 2012.

COUTO-VÁZQUEZ, A.; GARCÍA-MARCO, S.; GONZÁLEZ-PRIETO, S. J. Longterm effects of fire and three firefighting chemicals on a soil-plant system. International Journal of Wildland Fire, Roslyn, v. 20, n. 7, p. 856-865, 2011.

DAVIDE, A. C.; SILVA, E. A. A. da. Sementes florestais. In: DAVIDE, A. C.; SILVA, E. A. A. da (ed.). Produção de sementes e mudas de espécies florestais. Lavras: UFLA, 2008. 174 p.

FOOD AND AGRICULTURE ORGANIZATION OF THE UNITED NATIONS et al. Water quality and fish health. Rome, 1993. 59 p. (EIFAC Technical Paper, n. 54).

HAMILTON, S. J.; BUHL, K. J. Toxicity of fire retardant chemicals and fire suppressant foams to aquatic species. In: POULTON, B. et al. Toxicity of fire retardant and foam suppressant chemicals to plant and animal communities. Boise: Interagency Fire Coordination Committee, 1997.

IBAMA. Coordenação de Avaliação Ambiental de Substâncias e Produtos Perigosos. Parecer técnico, n. 514/2018-COASP/CGASQ/DIQUA, 20 de junho de 2018. Em atendimento à solicitação efetuada pela Diretoria de Proteção Ambiental (DIPRO) para que a Diretoria de Qualidade Ambiental (DIQUA) se manifeste tecnicamente sobre o uso de retardantes de chamas aplicáveis no combate a incêndios florestais. Brasília, 2018. 15 p. Disponível em: https:// www.ibama.gov.br/phocadownload/quimicos-e-biologicos/retardantes-de-chamas/2018-SEI_ IBAMA-Parecer-Tecnico-5142018-COASP-CGASQ-DIQUA.pdf. Acesso em: 14 out. 2018. 
LATHA, K.; KUMAR, S. S. Energy aware deforestation monitoring system. Australian Journal of Basic Applied Scienses, Perth, v. 10, n. 2, p. 283-289, 2016.

LIMA, D. C. de. et al. Volume de calda e concentração de retardantes do fogo em queimas controladas em área de eucalipto na transição Cerrado-Amazônia. Ciência Florestal, Santa Maria, v. 30, n. 1, p. 205-220, 2020a.

LIMA, D. C. de. et al. Comportamento do fogo em diferentes concentrações e tempos pósaplicação de retardantes em plantação de eucalipto na transição Cerrado-Amazônia no Brasil. Ciências Agrárias, Lisboa, v. 43, n. 1, p. 109-123, 2020.

LIODAKIS, S. et al. Testing the fire retardancy of Greek minerals hydromagnesite and huntite on WUI forest species Phillyrea latifolia L. Thermochimica Acta, Amsterdam, v. 469, p. 43-51, 2008.

LIODAKIS, S. et al. Thermal analysis of Pinus sylvestris L. wood samples treated with a new gelmineral mixture of short- and long-term fire retardants. Thermochimica Acta, Amsterdam, v. 568, p. 156-160, 2013.

LUNA, B. et al. Effects of a long-term fire retardant chemical (Fire-Trol 934) on seed viability and germination of plants growing in a burned Mediterranean area. International Journal of Wildland Fire, Roslyn, v. 16, n. 3, p. 349-359, 2007.

MACHADO FILHO, C. et al. Eficiência de um retardante de fogo de longa duração utilizado em incêndios florestais. Ciência Florestal, Santa Maria, v. 22, n. 2, p. 365-371, 2012.

MAGUIRE, J. D. Speed of germination aid in selection and evaluation for emergence and vigour. Crop Science, Madison, v. 2, p. 176-177, 1962.

MARSHALL, A.; WALLER, L.; LEKBERG, Y. Cascading effects of fire retardant on plant-microbe interactions, community composition, and invasion. Ecological Applications, Tempe, v. 26, n. 4, p. 996-1002, 2016.

MICHALOPOULOS, C. et al. Impact of a long-term fire retardant (FireTrol 931) on the leaching of $\mathrm{Ca}, \mathrm{Mg}$ and $\mathrm{K}$ from a Mediterranean forest loamy soil. Environmental Science and Pollution Research, Berlin, v. 23, n. 6, p. 5487-5494, 2016.

PAZDERU, K.; KOUDELA, M. Influence of hydrogel on germination of lettuce and onion seed at different moisture levels. Acta Universitatis Agriculturae et Silviculturae Mendelianae Brunensis, Brno, v. 61, n. 6, p. 1817-1822, 2013.

PLUCINSKI, M. P.; SULLIVAN, A. L.; HURLEY, R. J. A methodology for comparing the relative effectiveness of suppressant enhancers designed for the direct attack of wildfires. Fire Safety Journal, Oxford, v. 87, p. 71-79, 2017.

RAKOWSKA, J. et al. Selection of surfactants as main components of ecological wetting agent for effective extinguishing of forest and peat-bog fires. Chemical Papers, Bratislava, v. 68, n. 6, p. 823-833, 2014.

SILVA FILHO, E. A. da. Relatório de biodegradação de produto inibidor de chama: Hold Fire. Vitória: Laboratório de Físico-Química UFES, 2017. 4 p. 
SOARES, R. V.; BATISTA, A. C.; TETTO, A. F. Incêndios florestais: controle, efeitos e uso do fogo. 2. ed. Curitiba: UFPR, 2017. 255 p.

SOLER, M.; ÚBEDA, X. Evaluation of fire severity via analysis of photosynthetic pigments: Oak, eucalyptus and cork oak leaves in a Mediterranean forest. Journal of Environmental Management, London, v. 206, p. 65-68, 2018.

SONG, U. et al. Effects of three fire-suppressant foams on the germination and physiological responses of plants. Environmental Management, New York, v. 54, p. 865-874, 2014.

STEPHENS, S. L. et al. Drought, tree Mortality, and wildfire in forests adapted to frequent fire. BioScience, Washington, v. 68, n. 2, p. 77-88, 2018.

TANG, H. et al. Application of chitin hydrogels for seed germination, seedling growth of rapeseed. Journal Plant Growth Regulation, Berlin, v. 33, p. 195-201, 2014.

U.S. FOREST SERVICE. Ecological risk assessment of wildland fire-fighting chemicals: long-term fire retardants. Bellevue, 2015. Disponível em: https://www.fs.fed.us/rm/fire/wfcs/ documents/EcoRA-Retardants-PUBLIC-Dec2013-rev3_080614.pdf. Acesso em: 10 jan. 2019.

XIMENES, E. S. O. C. et al. Efeitos de retardantes de fogo sobre a emergência e crescimento inicial de Handroanthus ocrhaceus (Cham.) Mattos e Tabebuia rosealba (Ridl.) Sandwith. Ciência Florestal, Santa Maria, v. 31, n. 1, p. 367-392, 2021.

\section{Contribuição de Autoria}

\section{1 - Josiane Fernandes Keffer}

Engenheira Florestal, Me.

https://orcid.org/0000-0001-6134-7372•kefferjf@gmail.com

Contribuição: Curadoria de dados, Análise Formal, Investigação, Administração do projeto, Validação, Visualização de dados, Escrita - primeira redação, Escrita - revisão e edição

\section{2 - Adilson Pacheco de Souza}

Engenheiro Agrícola, Professor

https://orcid.org/0000-0003-4076-1093•pachecoufmt@gmail.com

Contribuição: Conceituação, Obtenção de financiamento, Metodologia, Administração do projeto, Recursos, Supervisão, Validação, Escrita - revisão e edição 


\section{3 - Rogério Antonio dos Santos}

Médico Veterinário

https://orcid.org/0000-0003-1090-5471•rads1500@gmail.com

Contribuição: Curadoria de dados, Investigação

\section{4 - Daiane Cristina de Lima}

Engenheira Florestal, Me.

https://orcid.org/0000-0001-8027-4500•daiac.lima1@gmail.com

Contribuição: Curadoria de dados, Investigação

\section{5 - Mariana Pizzatto}

Tecnóloga em Horticultura, Me., Técnica Agrícola

https://orcid.org/0000-0001-5751-0368•marianapizzatto23@gmail.com

Contribuição: Curadoria de dados, Investigação

\section{6 - Andréa Carvalho da Silva}

Engenheira Agrônoma, Professora

https://orcid.org/0000-0003-2921-3379•andcar1007@gmail.com

Contribuição: Conceituação, Obtenção de financiamento, Metodologia, Administração do projeto, Recursos, Supervisão, Escrita - revisão e edição

\section{Como citar este artigo}

Keffer, J. F.; Souza, A. P.; Santos, R. A.; Lima, D. C.; Pizzatto, M., Silva, A. C. Efeito de retardantes de fogo sobre a germinação de espécies florestais tropicais. Ciência Florestal, Santa Maria, v. 31, n. 2, p. 725-748, 2021. DOI 10.5902/1980509837161. Disponível em: https://doi. org/10.5902/1980509837161. Acesso em: xx mês-abreviado 2021. 